\title{
LA SANGRE Y LA TINTA
}

\author{
Dario Oses \\ Fundación Pablo Neruda \\ dosesbiblio@fundacionneruda.org
}

RESUMEN / ABSTRACT

Este artículo es un intento de aproximación a las singularidades de Pablo Neruda como lector, sobre la base de su doble condición de lector que hace un uso libre e intencionado de los textos, y de lector antilibresco. Examina dos vertientes de lecturas de Neruda, aquellas vinculadas con la tradición literaria -a las que el poeta denomina "el bosque de la literatura"-, y las otras, extra literarias, relacionadas con diversas disciplinas y con la historia del conocimiento. El artículo se ocupa también de la transición entre la lectura textual y la lectura del mundo en Neruda.

Palabras Clave: historia de la lectura, recepción, Neruda lector, prácticas de lectura.

This article intends to approach the peculiarities of Pablo Neruda as a reader, on the basis of his dual status of reader who makes a free and deliberate use of texts, and as a reader that neglects the intellectuality of books. In this light, two aspects of Neruda's readings are examined: those associated with the literary tradition which the poet calls "the forest of literature", and extra-literary readings related to varied disciplines and the history of knowledge. The article also discusses the transition between textual reading and the reading of the world in Neruda.

KEY WORDS: history of reading, reception, Neruda as a reader, reading practices.

Umberto Eco propone el ejercicio de leer las historias policiales de Rex Stout como novelas kafkianas, y comprueba que el texto soporta muy bien este uso. Pero advierte que si se intenta la operación inversa -leer El proceso, de Kafka como un relato policial- los resultados textuales son tan lamentables que "más valdría usar las páginas del libro para liarnos unos cigarrillos de marihuana" (Eco 86). 
Eco habla de la práctica y de la estética del uso libre, intencionado o malicioso de los textos. Entre las prácticas de lectura de Neruda podemos encontrar este uso libre e intencionado a partir del cual, muchas veces el poeta generó nuevos textos.

En su artículo "Sonata con recuerdos", Neruda anota:

Naturalmente nadie es enteramente nadie y todos son algunos en la creación imaginativa y creativa. Un solo personaje contiene muchos otros. Aunque nada novelístico, yo pienso que debe ser así a través de mi propia experiencia poética. Las sensaciones se entrecruzan, los crepúsculos del alba y de la noche se intercambian y los nombres, como sacos vacíos, cambian de carga en el hilo del tiempo (162).

El poeta parece aludir aquí a las distintas lecturas que puede aceptar un mismo texto en distintas épocas. Él mismo ejerció la libertad de buscar, desde su propio tiempo, nuevas propuestas de lectura para textos clásicos.

Así, en una conferencia radial en Montevideo, en 1939, que después incorporará a su libro Viajes, lee el célebre soneto “Amor constante más allá de la muerte", de Quevedo, desplazando el cuerpo de la amada quevedesca al cuerpo sufriente de la España Republicana.

La traducción es también una forma de relectura, y al hacer la de Romeo y Julieta, de Shakespeare, Neruda leyó esta obra, más allá del drama amoroso, como un alegato por la paz, en el Chile beligerante de 1973.

Releyó también a Whitman desde las movilizaciones pacifistas de los años 60. Recuerda el poeta que en 1968, luego de comprar un ejemplar de Hojas de hierba en Nueva York, al abrirlo lo primero que leyó fueron unas líneas en las que nunca antes había puesto atención: "Fuera los temas de la guerra/ fuera la guerra misma,/ desde aquí veo mi vista que tiembla./ No volvamos a mirar/ estos negros cuerpos mutilados" ("Al recibir" 118). Neruda inició uno de sus recitales en Nueva York con esos versos, que "tuvieron una respuesta instantánea" en el público que se puso de pie para aplaudir. Apunta Neruda: “[...] con las palabras del bardo Whitman, había tocado yo el corazón acongojado del pueblo norteamericano. La destrucción de las aldeas indefensas, el napalm quemando poblaciones vietnamitas, todo esto por la virtud de un poeta que vivió hace cien años [...] ("Al recibir" 118).

En su libro Incitación al nixonicidio y alabanza de la revolución chilena (1972) invoca y convoca a Whitman, a Quevedo y a Ercilla. Con este último cierra el libro. Incluye los célebres versos de La Araucana: "Chile, fértil provincia señalada/ en la región antártica famosa [...]. La gente que produce 
es tan granada,/tan soberbia, gallarda y belicosa,/ que no ha sido por rey jamás regida,/ ni a extranjero dominio sometida" (740). Sin cambiar una coma de este texto, por el solo hecho de incluirlo en el panorama político contemporáneo de nuestro país, desplaza su significado, desde las guerras de la Conquista del siglo XVI al enfrentamiento del Chile de la Unidad Popular con el imperialismo norteamericano, en el siglo XX. Luego usa cada uno de los versos de Ercilla, a la manera de los "pie forzados" de la poesía popular, para hacer un poema a dos voces.

Neruda relee a algunos de sus autores clásicos favoritos: Quevedo, Whitman, Shakespeare, Ercilla, buscando sentidos distintos de los que construyeron las lecturas de los contemporáneos de esos autores. Su lectura, en general, es hecha desde una visión de mundo que sitúa la paz universal, los movimientos populares emancipatorios y las luchas antifascistas y antiimperialistas como valores cardinales. Es pertinente recordar algunas consideraciones de Jauss sobre los clásicos, a los que considera no como arquetipos platónicos, sustraídos del tiempo, sino como obras capaces de abrir horizontes nuevos en su propio tiempo y de prefigurar experiencias futuras. La "lectura distanciada" de los clásicos -que es la que hace Neruda- los libera del horizonte histórico que condicionó su génesis y hace posible la percepción de la diferencia entre el horizonte contemporáneo a la producción de la obra y el del presente del lector.

Como advierte Eco, la lectura "libre, intencionada y maliciosa" puede llevar a resultados desastrosos. Nos parece que es necesario tener un fino sentido de lector, para ejercer la libertad de la lectura sin traspasar los límites dentro de los cuales el texto sea capaz de admitir esa libertad. Neruda tuvo ese sentido, no solo cuando leía a los clásicos, sino también con la literatura de entretención.

En "Conversación frente al océano", la extensa entrevista que le hizo Rita Guibert en enero de 1970, al hablar sobre su predilección por la novela negra, el poeta dijo:

Casi todos los novelistas norteamericanos de esta escuela policial son tal vez los más severos críticos del desmoronamiento de la sociedad norteamericana en la época del capitalismo. No hay denuncia más fuerte que la de la novela policial -la de la verdadera gran novela policial-de estos últimos tiempos sobre el ajetreo y la corrupción de políticos y policías, la influencia del dinero en las grandes ciudades, la corrupción que asoma por todas partes en el sistema norteamericano, 'in the American Way of Life'. Es posiblemente el testimonio más dramático de una época y quizás la acusación menos permanente, 
dado que los libros policiales no son tomados en cuenta por la crítica literaria. Pero, aunque transitoria, no deja de ser una denuncia profunda de una época de decadencia del imperio norteamericano (1157-1158).

Poco antes de hacer estas declaraciones, en la misma entrevista, Neruda hablaba de su admiración por la novela de Eric Ambler, A Coffin for Dimitrios por "la perfección fundamental, la intriga extraordinaria y el ámbito misterioso" $(1157)^{1}$. Hasta ahí Neruda había procedido como un lector implicado en el contrato de lectura convencional del género: la propuesta de una intriga y el desafío a que el lector la resuelva antes de que el autor le revele la solución. Pero luego, como hemos visto, se desvía intencionalmente de esta lectura de la novela policíaca como relato de suspenso, a otra, como crítica a la sociedad capitalista ${ }^{2}$. Desde luego, en esta última lectura podría haber malicia, ya que Neruda busca y encuentra en la novela negra la confirmación de su visión política. Pareciera existir entonces una voluntad de torcer la lectura voluntariosamente, para orientarla en un sentido predeterminado. Pero la novela negra admite esa torsión, y esto porque -como me lo hizo notar en una entrevista Ricardo Piglia- muchos de sus autores, como Dash Hammeth, Raymond Chandler y Horace McCoy, eran de izquierda y buscaban "una forma de hacer literatura social, denunciando la corrupción del poder, del gran dinero, las relaciones y complicidades del mundo político con el de los negocios, etc..." (Piglia 35).

Es legítima, por lo tanto, esta lectura de Neruda, puesto que está descubriendo la intención encubierta de autores que para eludir al macartismo criticaban al capitalismo norteamericano a través de la novela negra.

De modo que las actualizaciones y torsiones de significados que hace el poeta son operaciones que, en general, los textos admiten. Neruda no violenta los textos que lee. Sí busca lecturas nuevas. Lee con libertad, casi siempre. Casi, porque entre principios de los 40 y mediados de los 50, leyó

1 Debe tratarse de un lapsus de Neruda al contestar a la entrevistadora. El verdadero nombre de la novela es The mask of Dimitrios.

2 Paul Ricœur comenta: “[...] la retórica de la ficción pone en escena a un autor implicado que mediante una operación de seducción, intenta hacer al lector idéntico a él mismo. Pero cuando el lector, descubriendo su lugar prescrito por el texto, se siente no ya seducido, sino aterrorizado, le queda como único recurso distanciarse del texto y tomar conciencia, del modo más claro posible, de la desviación entre las expectativas que el texto desarrolla y las suyas propias, como individuo condenado a la cotidianidad y como miembro del público culto, formado por toda una tradición de lecturas" (898-899). 
muy acríticamente a los autores del canon oficial soviético, como Alexander Fadéiev, Boris Polevói, Mijail Sholojov, Konstantin Fedin y Fiodor Gládkov, entre otros. También leyó desde el realismo socialista a otros escritores. Desde luego condenó a los pro fascistas: Pound, Céline, La Rochelle, y luego a otros, como Faulkner, Sartre y Eliot, por su decadentismo burgués, y por ser lo que él consideraba las emanaciones de un mundo agonizante. Pero después de 1956 se retracta y se declara contrario a todo dogmatismo. En su segunda biblioteca se encuentran varios libros de Céline, entre ellos, la reivindicatoria edición de La Pléiade de Viaje al fin de la noche, de 1962, y también libros de autores rusos proscritos, como Mijail Bulgákov y Alexander Solzhenitsyn.

David Schidlowsky cita la entrevista de 1958, que se publica en español en la revista Vea, de Santiago, con el título "Neruda confiesa sus errores", y que es la traducción de una entrevista que el poeta había dado en Praga, publicada originalmente en checo. En ésta se declara "contrario a cualquier forma de dogmatismo" y acepta que leyó dogmáticamente a algunos escritores: "Condené por ejemplo, a vuestros compatriotas Rilke y Kafka, sin siquiera conocer bien su obra" (Las furias 863-864). Agrega que los ha releído "concienzudamente y a fondo" y que ahora opina "que en las obras de Rilke hay mucho de la más espléndida poesía, y que en la obra de Kafka hay mucho de un penetrante y específico realismo" (Las furias 863-864) ${ }^{3}$.

Esta lectura "concienzuda y a fondo" indica, desde luego, el cambio radical que se produce en relación con su anterior "lectura dogmática".

Por otra parte, Neruda se autocalificó insistentemente como antilibresco. Desde muy joven fue un lector voraz. Además desarrolló una devoción por el libro, que lo llevó a la bibliofilia. Sin embargo, en forma persistente colocó al libro en conflicto con la vida, y se declaró partidario de esta última. En 1954 decía: "Mi generación fue anti-libresca y antiliteraria por reacción contra la exquisitez decadente del momento. Éramos enemigos jurados del vampirismo, de la nocturnidad, del alcaloide espiritual. Fuimos hijos naturales de la vida" (“El rector” 948-949).

3 En el discurso que leyó en el Congreso Latinoamericano de Partidarios de la Paz, en México, en 1949, Neruda había dicho que en los últimos años "maestros snobs se han apoderado de Kafka, de Rilke, de todos los laberintos que no tengan salida, de todas las metafísicas que han ido cayendo, como cajones vacíos desde el tren de la historia [...]" ("Mi país, como ustedes saben..." 765). 
En su "Oda al libro I", de Odas elementales (1954), proclama: "Libro, cuando te cierro/ abro la vida..." (142) o "Libro, déjame libre" (143). Y en "Oda a la alegría" dice: "Hoy, alegría,/ encontrada en la calle, / lejos de todo libro acompáñame [...]” (53).

Pero esta condición antilibresca es problemática, porque poco después exalta al libro. En "Oda al libro II", también de Odas elementales, dice: "Libro/hermoso,/libro,/ mínimo bosque [...]/eres/ matutino y nocturno,/ cereal, oceánico [...]" (144). En "Oda a la tipografía”, de Nuevas odas elementales (1956), habla de las letras "extendiendo / el tesoro acumulado, / esparciendo de pronto / la lentitud de la sabiduría / sobre la mesa / como una baraja, / todo el humus / secreto /de los siglos [...]” (413-414).

Así, se advierte en Neruda una modulación permanente entre el entusiasmo y el desencanto por el libro y la lectura.

Tal vez el texto en que manifiesta un mayor desencanto y en que lo hace de la manera más inquietante -entre otras cosas, porque implica a dos de sus autores favoritos: Quevedo y Lautréamont- es una parte del poema "El sobrino de occidente", de Cantos ceremoniales (1961):

Pregunto libro a libro, son las puertas, hay alguien/ que se asoma y responde y luego no hay/ respuesta, se fueron las hojas,/ se golpea a la entrada del capítulo, / se fue Pascal, huyó con los Tres Mosqueteros, / Lautréamont cayó de su tela de araña, / Quevedo, el preso prófugo, el aprendiz de muerto/ galopa en su esqueleto de caballo/ y, en suma, no responden en los libros: / se fueron todos, la casa está vacía. / Y cuando abres la puerta hay un espejo/ en que te ves entero y te da frío (1019-1020).

Pocos años después, en Memorial de Isla Negra (1964), escribe: "Los libros tejieron, cavaron,/deslizaron su serpentina /y poco a poco, detrás /de las cosas, de los trabajos,/surgió como un olor amargo/ con la claridad de la sal/ el árbol del conocimiento" (1169).

Y en sus memorias, Confieso que he vivido (1974) anota: "Me place el libro, la densa materia del trabajo poético, el bosque de la literatura..." (401).

Así, para Neruda, sobre "el humus secreto de los siglos" crecen "el árbol del conocimiento", por una parte, y "el bosque de la literatura", por otra. Esta distinción me parece interesante, ya que Neruda fue un gran lector de poesía y de novelas. Pero también leyó y coleccionó los libros relacionados con "el árbol del conocimiento": enciclopedias; historia natural; historiografía, especialmente hispanoamericana, y libros de exploraciones y de viajes. 
Estas otras narrativas no solo son textuales. Al poeta le gustaban los libros con grabados, fotos, planos de antiguas ciudades y mapas. Neruda leyó las ilustraciones y ésta podría ser la transición desde su lectura del texto a su lectura del mundo.

Neruda se deslumbró también con la materialidad del libro, con su visualidad y su consistencia, y con los oficios y las artes del libro. En "Oda a la tipografía”, rinde homenaje a los impresores clásicos: los Aldos, Bodonis y Elzevires. El tono de esta oda es de celebración del soporte material de la palabra y también de lo que se ha llamado la "galaxia de Gutenberg", es decir, un universo construido por la palabra escrita: "Debajo/ de las nuevas pirámides escritas/ la letra/ estaba viva,/ el alfabeto ardiendo [...]" (413). El poeta celebra este mundo donde la letra llena "el corazón y los ojos" de los hombres y tiene la capacidad de fecundar a las cosas, al canto y a la memoria, y además posee una enorme potencia emancipadora: "La letra/ fue la madre de las nuevas banderas, /las letras/ procrearon/ las estrellas/ terrestres/ y el canto, el himno ardiente /que reúne /a los pueblos/[...]" (415-416).

Sin embargo, este poeta deslumbrado por el libro, su irradiación, su arte y su materia, cada cierto tiempo y entre las alabanzas que hace al libro, insiste en declararse antilibresco.

Neruda construye varias autorrepresentaciones de poeta antilibresco, por ejemplo, las del poeta natural, del hombre invisible, del poeta que asume la voz del colectivo humano. Federico García Lorca lo presentó alguna vez como un poeta "más cerca de la sangre que de la tinta" (249). Sin embargo, parte importante de la poesía de Neruda tiene fuentes bibliográficas. Enrico Mario Santí ha rastreado estas fuentes para Canto general. También las hay para otras obras de Neruda, entre ellas los extensos poemas "Fulgor y muerte de Joaquín Murieta" y "Lord Cochrane de Chile", ambos de La barcarola, (1967), y para la obra de teatro Fulgor y muerte de Joaquín Murieta. Bandido chileno injusticiado en California el 23 de julio de 1853 (1967). Selena Millares rastreó la "amplia red de voces distantes y dispersas" (El fuego 191) que se traslucen tanto en el poema como en la obra dramática sobre Murieta, señalando las fuentes en las que Neruda investigó, que van desde novelas hasta crónicas.

Por otra parte, Millares anota que "tras su aparente actitud antilibresca -un signo generacional que cultivó como hijo de la vanguardia- latía la devoción hacia la tradición poética, con la que mantuvo un controvertido diálogo: fecundo, constante y a menudo secreto" ("Pablo Neruda" LV). La autora examina con singular brillo este "diálogo" en su libro El fuego y la 
fragua, es decir, se ocupa principalmente de "el bosque de la literatura" en la obra de Neruda. Abordaremos, más adelante, la otra vertiente: la de "el árbol del conocimiento".

Por último, Millares examina las voces del mito que afloran en la poesía de Neruda, en tres vertientes: la clásica grecolatina, la bíblica y la americana. Podríamos agregar la presencia de ciertas matrices del relato mítico en la obra de Neruda, por ejemplo en el Discurso de Estocolmo (1971), en cuya primera parte el poeta relata el viaje por la cordillera que hizo a principios de 1949, cuando salió clandestinamente del país. En el discurso señalado, Neruda desliga este viaje de sus circunstancias históricas, centrándose más bien en una serie de pruebas, de ritos de pasaje, de comunión con los demás hombres, y de purificación y renacimiento, para alcanzar, por una parte, la libertad y, por otra, la revelación de lo que debe ser la poesía. Podríamos también agregar a las numerosas fuentes literarias que aporta Millares: autores como Ovidio, Garcilaso de la Vega, Juan de Jáuregui, Lope, Calderón y la Biblia, entre otros, los tratados de mitología de Robert Graves que se encuentran en su segunda biblioteca: Mitos hebreos, Mitos griegos, y Diosa Blanca. Historia comparada del mito poético.

Examinemos ahora qué es lo que quiere decir Neruda cuando habla de lo antilibresco.

El 24 de abril de 1929 le escribía desde Ceilán una carta a Héctor Eandi, en la que decía:

Borges, que usted me menciona, me parece más preocupado de problemas de la cultura y de la sociedad, que no me seducen, que no son humanos. A mí me gustan los grandes vinos, el amor, los sufrimientos y los libros como consuelo a la inevitable soledad. Tengo hasta cierto desprecio por la cultura, como interpretación de las cosas, me parece mejor un conocimiento sin antecedentes, una absorción física del mundo [...] (“Carta de Neruda a Héctor Eandi” 942-943).

En materia de lecturas, el poeta expresó algunas preferencias y aversiones generales. En Confieso que he vivido escribe: "Me place el libro [...] pero no las etiquetas de las escuelas. Quiero libros sin escuelas y sin clasificar, como la vida" (401).

$\mathrm{Y}$ en esas mismas Memorias, anota:

Nunca he tenido interés en las definiciones, en las etiquetas. Me aburren a muerte las discusiones estéticas. No disminuyo a quienes 
las sustentan, sino que me siento ajeno tanto a la partida de nacimiento como al post mortem de la creación literaria. "Que nada exterior llegue a mandar en mí", dijo Walt Whitman. Y la parafernalia de la literatura, con todos sus méritos, no debe sustituir a la desnuda creación (457).

Para Neruda parece haber dos tipos de lectura: aquella directa, transparente, casi natural, y la otra, la que se hace con la mediación de aparatos analíticos, con lo que él llama "la parafernalia de la literatura". También habría textos más o menos apropiados para uno y otro lector. Así, la poesía, capaz de reproducir "el fuego y la fertilidad" de la naturaleza, merecería una lectura afín con esa potencia reproductora: "en la casa de la poesía no permanece nada sino lo que fue escrito con sangre para ser escuchado por la sangre" ("Conducta y poesía" 384), apuntó el poeta en uno de los prólogos de Caballo Verde para la Poesía y esta "escucha por la sangre" es, desde luego, una posibilidad de lectura.

Pero también habría textos que pueden ser leídos tanto desde la sangre como desde la tinta, en el poema "Los libros", de Memorial de Isla Negra, dice: "Libros sagrados y sobados, libros/ devorados, devoradores, / secretos, / en las faltriqueras: / Nietzsche, con olor a membrillos, / y subrepticio y subterráneo, / Gorki caminaba conmigo" (1169).

Así, en los primeros versos de este poema, el libro aparece, de acuerdo a sus posibilidades de lectura, como "sagrado" y "sobado"; como secreto, pero en las faltriqueras, donde se llevan las cosas de uso corriente. Ahí están el oscuro Nietzsche que puede ser devuelto a la corriente cotidiana por su proximidad con el membrillo, y Gorki, por un lado "subrepticio y subterráneo", pero que camina al lado del poeta.

Hay un testimonio de Neruda que es particularmente elocuente en cuanto a cómo podía transitar fácilmente desde una posición antilibresca hacia el interés por el texto y por el libro:

En aquellos años antes de 1950 andaba yo perseguido, transmigrante de casa en casa, de misterio en misterio [...]. En cada sitio yo hurgaba en los papeles, los libros, inexistentes en algunas partes, abundantes en otras. En casa de mi benefactor de turno, mi amigo don Julio Vega, me encontré con un viejo Boletín de Historia y Geografía, descabalgado y amarillento por la edad. Abrí las páginas para no leerlas, tanto tedio parecían exhalar. De repente saltó del tiempo amarillo un relato que me atravesó el corazón como una lanza. Eran las páginas en que el coronel Pueyrredón, ya anciano, recordaba su vida militar y su 
encuentro con el general chileno José Miguel Carrera, de quien fue prisionero ("El coronel Pueyrredón" 13).

El historial de lector del poeta sirve también para explorar las complejidades de esta figura del lector antilibresco.

A lo largo de su vida, Neruda cumplió misiones diplomáticas, algunas de gran complejidad, como la de embarcar hacia Chile a los refugiados españoles desde Francia, en 1939; organizó congresos literarios y agrupaciones antifascistas; vivió un tiempo como prófugo; tuvo una intensa actividad política, festiva y social; viajó por todo el mundo; escribió decenas de libros de poesía, artículos, traducciones y discursos; tuvo muchos amores, algunos apacibles y otros no tanto, pero siempre encontró la ocasión para leer. Vivió y leyó y se las arregló para hacerlo de manera que el tiempo de la lectura no suspendiera el de la vida. Si en algún momento estableció una polarización entre vida y lectura, finalmente, para él, fueron haciéndose cada vez más tenues los límites entre ambas.

¿Por qué lee? Siempre leyó por placer. Pero la lectura para él también fue una forma inicial de apertura hacia el mundo. Desde su habitación de niño, en el aislamiento de la noche y de la lluvia interminable, despegaba hacia los océanos y las islas de los piratas de Mompracem. Leía para explorar y conocer. La lectura fue la primera forma del viaje. En ella, como en los periplos que se describen en los antiguos libros de exploraciones que más tarde tuvo el poeta, iba encontrando lugares insospechados, regiones de misterios y maravillas: "Qué soledad la de un pequeño niño poeta, vestido de negro, en la frontera espaciosa y terrible. La vida y los libros poco a poco me van dejando entrever misterios abrumadores" (Confieso que he vivido 32) -escribió al recordar sus primeras lecturas.

El ya citado poema "El sobrino de Occidente" comienza con una evocación de la infancia, de cuando un tío, al que llama Manuel, le trae uno de esos libros, que contiene relatos de viajes imaginarios, y cuya lectura remite al mundo: "El libro era Simbad el marino y supe de pronto/ que más allá de la lluvia estaba el mundo, /claro como un melón resbaloso y florido" (1019).

En ese mismo poema, Neruda sigue hablando de sus años juveniles, en los que la letra y la vida se alternan y se confunden: "Veinte años! Naufragio!/ Delirante batalla,/ la letra/ y la letra,/ el azul, el amor,/ y Simbad sin orillas,/ y entonces/ la noche delgada,/ la luz crepitante del vino" (1019). 
Su biógrafo Volodia Teitelboim indica que el joven Neruda "salta desordenadamente" ("Neruda" 37) desde los libros de aventuras a Vargas Vila y luego a otros autores, como Strindberg y Felipe Trigo.

El tránsito desde Salgari a Trigo podría coincidir con el paso a la adolescencia del poeta, y con el despertar de su sexualidad. Tal vez la lectura de autores como Felipe Trigo -“el sicalíptico español”, según Teitelboim- anticipó el conocimiento del amor y la sexualidad. Es posible que ésta y aquel sean parte de los "misterios abrumadores" a que se refiere el poeta. La lectura habría sido entonces una forma de anticipar las experiencias fundamentales de la vida, entre ellas, la amorosa. Más adelante veremos cómo Neruda se ocupará de contrastar los contenidos de sus lecturas con su experiencia directa del mundo. Así, vive en esta alternancia entre la letra y la vida, entre la sangre y la tinta.

Podríamos conjeturar que Neruda se inicia en la lectura entre los 7 y los 10 años, es decir, entre 1911 y 1914, y no deja de leer hasta el momento de su muerte. Su universo de lecturas comprende, cronológicamente, desde los libros de Emilio Salgari hasta los de los autores del boom de la narrativa hispanoamericana, y hasta Norman Mailer.

La historia de Neruda como lector, inevitablemente se entrelaza con los cambios culturales que se producen en las primeras décadas del siglo XX. El anarquismo juvenil de Neruda, su vida bohemia santiaguina y sus lecturas de los años 20, podrían considerarse como gestos de desacato contra el sistema oligárquico que estaba entrando en crisis en ese tiempo. La lectura y la creación poética fueron una forma de rebeldía contra aquel modelo autoritario patriarcal que se replicaba en todos los niveles de la sociedad, incluyendo la familia (recordemos que el mismo padre de Neruda persiguió con saña el oficio de poeta de su hijo, hasta el punto de quemarle sus manuscritos y libros).

Neruda también lee para escribir. Estudia pedagogía en francés, no para ser profesor, sino para leer a los poetas franceses modernos en su idioma, y a escritores rusos, alemanes y nórdicos en traducciones al francés, cuando no las había al español. Desde muy joven comienza a construir su propio canon, con la lectura de Whitman, Rimbaud, Maiakowsky, Baudelaire, Víctor Hugo, luego Shakespeare, Quevedo, Góngora, Ercilla, Villamediana, Lautréamont, Darío y algunos otros autores a los que siempre vuelve.

Para Neruda, la lectura era una forma de situarse en la corriente continua de la poesía o en "el bosque de la literatura": "El mundo de las artes es un gran taller en el que todos trabajan y se ayudan, aunque no lo sepan ni lo crean [...] estamos ayudados por el trabajo de los que nos precedieron y se sabe que no hay Rubén Darío sin Góngora, ni Apollinaire sin Rimbaud, ni 
Baudelaire sin Lamartine, ni Pablo Neruda sin todos ellos juntos" ("Mariano Latorre" 1095).

Sus lecturas infantiles de libros de aventuras continuaron en la juventud con otros autores: principalmente Loti y Conrad, y posteriormente Melville, Stevenson y con los muchos libros de expediciones marinas, viajes de exploración e historias de piratas que el poeta dejó en sus bibliotecas.

En 1927 viaja a Oriente, a los mismos parajes que ya había visitado imaginariamente a través de los libros. En una carta a Eandi, desde Ceilán, de 24 de abril de 1929, le dice que se siente como uno de los vagabundos de Conrad. Y en una crónica de viaje escrita en Singapur, comenta con desolación que el malayo ya no es noble sino servil. "Eso han devenido los viejos héroes piratas: ahí están los nietos de los tigres de la Malasia. Los herederos de Sandokán han muerto" ("Diurno" 341) -anota.

Neruda contrasta el mundo con sus referencias literarias. Es curiosa esta comparación de su visión directa del mundo con la de la narrativa de ficción, como la de Salgari. Al hacerlo, parece estar otorgándole a la ficción una credibilidad semejante a la de su observación directa de la realidad.

Para Neruda, los libros, lo mismo que el planeta, contienen a los seres y a los objetos del mundo. Cuando el poeta abre sus atlas de historia natural, encuentra pájaros, peces, moluscos, animales de todos los continentes y los mares. Sus propios libros -los de su autoría- sobre los pájaros, las piedras, el océano son una forma de leer el mundo natural. Los límites entre la lectura de libros y la lectura del mundo se van haciendo cada vez más tenues.

El poeta se sitúa en la tradición de la cultura occidental de la "lectura del mundo" o de "el mundo como libro". Para Calasso, "el simbolismo del Liber mundi tiene una historia muy larga y compleja: la misma imagen reaparece en edades lejanas, en contextos diversos (30). Borges anota que a los cristianos, la creencia de que la divinidad había escrito un libro "los movió a imaginar que había escrito dos y que el otro era el universo" (161). Borges cita luego a Carlyle, quien propuso que la historia universal "es una Escritura Sagrada que desciframos y escribimos inciertamente y en la que también nos escriben" (Cit. en Borges 162). Agrega Borges que para Mallarmé "el mundo existe para un libro" (162) y, que según León Bloy, "somos versículos palabras o letras de un libro mágico, y ese libro incesante es la única cosa que hay en el mundo: es, mejor dicho, el mundo" (Cit. en Borges 162-163). En 1774, Goethe escribía: "Ved cómo la Naturaleza es un libro vivo..." (Cit. en Manguel 220), y en 1892 Whitman anotaba: "En todo objeto, montaña, árbol y estrella; en todo nacimiento y vida,/ parte de cada 
uno $[\ldots]$ surgiendo de cada uno [...] el significado detrás de lo aparente,/ la cifra mística espera oculta" (Cit. en Manguel 220).

En su "Oda a la tipografía", Neruda habla de su propia lectura del mundo natural: "En todo, / en la estela/ del gusano/ se lee,/ en la rosa se lee, / las raíces/ están llenas de letras/ retorcidas/ por la humedad del bosque/ y en el cielo/ de Isla Negra, en la noche,/ leo,/ leo/ en/ el firmamento frío/ de la costa [...]" (418).

En 1962, declaraba: “[...] mi libro más grande, más extenso, ha sido este libro que llamamos Chile. Nunca he dejado de leer la patria, nunca he separado los ojos del largo territorio [...]". En esa misma ocasión recordaba sus primeras lecturas de la naturaleza: "Yo aprendí desde muy pequeño a leer el lomo de las lagartijas que estaban como esmeraldas sobre los viejos troncos de la selva sureña [...]" (Neruda, "Mariano Latorre" 1096).

En el poema "A una estatua de proa", de Gran Océano, Canto general (1950), Neruda relata su encuentro en Magallanes, en el extremo sur de Chile, con uno de los mascarones que pasó a formar parte de su colección. Le dice: "Para mí tu belleza guarda todo el perfume, / todo el ácido errante, toda la noche oscura. / Y en tu empinado pecho de lámpara o de diosa, / torre turgente, inmóvil amor, vive la vida" (791).

El poeta se apropia de este fragmento de una embarcación, y en ese fragmento busca la totalidad del mar, del viaje, de la noche, así como otros trataron de descifrar las realidades divinas e invisibles o los significados ocultos, a las que remite el alfabeto de objetos tangibles en que está escrito el libro del mundo. "Muchas cosas/ me lo dijeron todo" (772), escribió el poeta en su "Oda a las cosas", de Navegaciones y regresos (1959).

Se advierte cierta continuidad entre esa lectura del mundo con el proyecto de hacer el inventario poético del mundo, que requirió tanto de la experiencia directa de la vida como de los libros, y puede encontrarse cierta correspondencia entre el poetizar la compleja diversidad del mundo, y el reunir las enciclopedias y bibliotecas, que dan cuenta de ese mundo y a la vez son parte de él. Los libros y el mundo aparecen así como dos infinitas cajas de sorpresas que se contienen mutuamente: el poeta abre el mundo y encuentra libros, luego abre los libros y allí está el mundo.

Como indica Alberto Manguel, "para Whitman, texto, autor, lector y mundo se reflejaban mutuamente en el acto de leer, acto cuyo significado él ampliaba hasta abarcar toda la actividad humana, y también el universo en el que todo ocurría" (225). 
Creo que para Neruda, las contradicciones implícitas en la figura del lector antilibresco se resuelven en la medida en que se diluyen los límites entre las lecturas del poeta con sus viajes y su observación, absorción y experiencia directa del mundo. Así, por ejemplo, se advierte cierta continuidad entre su lectura directa e inicial del mundo y la de sus antiguos libros de historia natural: "Estos libros zoológicos y botánicos me apasionaron desde siempre - escribió. Continuaban mi infancia, me traían el mundo infinito, el laberinto inacabable de la naturaleza" (Neruda, "El rector" 948). Cuando el poeta dice que estos libros continuaban su infancia, podría estar refiriéndose a su deslumbramiento inicial por el bosque nativo y por el mar. De modo que el tránsito entre la lectura textual y la del mundo circula en ambos sentidos.

Entre las grandes historias naturales que tuvo el poeta se encuentra la de Ulises Aldrovandi (1522-1605), uno de los grandes naturalistas del Renacimiento. Su obra, que empezó a publicarse en 1599, pretendía comprender todo cuanto se sabía en su época acerca del mundo natural (como Neruda, Aldrovandi tuvo un proyecto que pretendía abarcar una totalidad). Michel Foucault, en Las palabras y las cosas, lo señala en la historia del conocimiento como un hito en el que se establece, como problema, el de la distancia entre la naturaleza y su representación.

Aldrovandi fundó el primer Museo Público de Bolonia, aportando piezas que él mismo había recolectado. Sus colecciones fueron valiosas, tanto que durante las invasiones napoleónicas las trasladaron a Francia. Aldrovandi fue un coleccionista, lo mismo que Neruda. Aseguró que no había descrito cosa alguna sin haberla tocado con su propia mano y sin haber estudiado su anatomía. Es decir, trató de reducir la distancia entre la naturaleza y su representación, garantizando la correspondencia entre ambas. De ahí la importancia de tener las piezas al alcance de la mano. Aldrovandi no solo representó la naturaleza a través de la palabra. Sus libros fueron enriquecidos con gran cantidad de ilustraciones, preparadas por artistas famosos de la época. Al recorrer las páginas de la obra de Aldrovandi, especialmente de su ornitología, no puede dejar de recordarse algunas magníficas ediciones de la poesía de Neruda, como Arte de pájaros, que también fue ilustrada por grandes artistas chilenos contemporáneos y en donde el poeta incluye a especies reales y a otras imaginarias, lo mismo que las antiguas historias naturales, que no solo describían las especies, sino que daban cuenta de las creencias que los hombres tenían sobre ellas, los usos medicinales que se les atribuían, y en el camino, a veces tomaban como reales, especies que más que de los bosques, las montañas o los mares, venían de los bestiarios de la zoología fantástica. 
Los libros vinculados con "el árbol del conocimiento" aportan a la poesía y a la prosa de Neruda ciertos modelos como el de la enciclopedia: Canto general; los libros de exploraciones y viajes: Viajes, y los repertorios, catálogos y taxonomías del mundo natural: Arte de pájaros, Las piedras de Chile, Las piedras del cielo, Maremoto.

Aldrovandi ha de haber tenido su museo particular, antes de donar sus colecciones al de la ciudad de Bolonia. Un adelanto, tal vez, del "gabinete de curiosidades" de los sabios del siglo XVII, donde se reunía, por una parte, maravillas anatómicas, caracolas marinas, fósiles y esqueletos de animales extraños y, por otra, esferas armilares, libros y catálogos ilustrados, mapas y atlas. Es decir, la naturaleza y los instrumentos para su representación.

Neruda creó su propio gabinete de curiosidades, con sus colecciones de caracolas, mariposas y otras especies como los dientes de narval y de cachalotes, junto a sus bibliotecas. Desde ahí construyó, en parte, su representación poética de la naturaleza y el mundo. Las casas del poeta, llenas de objetos curiosos, de "singularidades evocadoras", como denominó Marcel Granet las colecciones de un parque real chino, son una imago mundi.

Escribir desde estos gabinetes también es parte de la tradición de la cultura occidental. Calasso señala que Thomas Browne, en su casa de Norwich, había reunido entre el museo, la biblioteca y el laboratorio, una especie de epítome del siglo. Agrega que se puede considerar su obra escrita "como el doble verbal" de aquel compendio de objetos que representan el mundo.

En las descripciones que se hacen tanto en las antiguas historias naturales como en los catastros científicos modernos, persiste el problema de la distancia entre la naturaleza y su representación. Además, sigue existiendo una zona misteriosa del mundo, irreductible a la taxonomía. Con su poesía, Neruda intenta una aproximación a ese misterio, y trata de reducir ese espacio entre la naturaleza y su representación. En 1939, aludió a aquel espacio de misterio cuando se autodefinió como "el poeta más ensimismado en la contemplación de la tierra", y cuando dijo: "yo he querido romper con mi pequeña y desordenada poesía el cerco de misterio que rodea al cristal, a la madera, a la piedra" ("España no ha muerto" 427-428).

\section{BIBLIOGRAFÍA}

Borges, Jorge Luis. "Del culto a los libros". Otras inquisiciones. Buenos Aires: Emecé Editores, 1960. 157-163. 
Calasso, Roberto. Los jeroglificos de Sir Thomas Browne. México D.F.: Fondo de Cultura Económica, 2010.

Eco, Umberto. Lector in fabula. La cooperación interpretativa en el texto narrativo. Trad. Ricardo Pochtar. Barcelona: Editorial Lumen, 1981.

García Lorca, Federico. "Presentación de Pablo Neruda". Obras completas. Tomo III. Prosa. Edición de Miguel García -Posada. Barcelona: Galaxia Gutenberg/Círculo de Lectores, 1997.

Manguel, Alberto. Una historia de la lectura. Bogotá: Grupo Editorial Norma, 1999.

Millares, Selena. Neruda: el fuego y la fragua. Salamanca: Ediciones Universidad de Salamanca, 2008.

"Pablo Neruda y la tradición poética: sombra y luz de un diálogo entre siglos". Neruda, Pablo. Antología general. Edición conmemorativa de la Real Academia Española y la Asociación de Academias de la Lengua Española. Lima: Alfaguara, 2010. LV-LXXX.

Neruda, Pablo. "El coronel Pueyrredón y la sombra que pasa”. J. M. C. El húsar desdichado. Libro que contiene la memoria de Manuel A. Pueyrredón, poesía y canciones que tratan de la vida y la muerte de don José Miguel Carrera. Buenos Aires: Ediciones de la Flor Alta, 1972.

Confieso que he vivido. Barcelona: RBA Editores, 1999.

Canto general. Obras completas. Tomo I. De "Crepusculario" a "Las uvas y el viento". 1954-1964. Ed. Hernán Loyola con el asesoramiento de Saúl Yurkievich. Barcelona: Galaxia Gutenberg/Círculo de Lectores, 1999. 417-837.

Odas elementales. Obras completas. Tomo II. De "Odas elementales" a "Memorial de Isla Negra”. 1954-1964. Ed. Hernán Loyola. Barcelona: Galaxia Gutenberg/Círculo de Lectores, 1999. 39-256.

Nuevas odas elementales. Obras completas. Tomo II. De "Odas elementales" a "Memorial de Isla Negra". 1954-1964. Ed. Hernán Loyola. Barcelona: Galaxia Gutenberg/ Círculo de Lectores, 1999. 259-433.

Navegaciones y regresos. Obras completas. Tomo II. De "Odas elementales" a "Memorial de Isla Negra”. 1954-1964. Ed. Hernán Loyola. Barcelona: Galaxia Gutenberg/ Círculo de Lectores, 1999. 743-850.

Cantos ceremoniales. Obras completas. Tomo II. De "Odas elementales" a "Memorial de Isla Negra”. 1954-1964. Ed. Hernán Loyola. Barcelona: Galaxia Gutenberg/Círculo de Lectores, 1999. 1019-1087.

Memorial de Isla Negra. Obras completas. Tomo II. De "Odas elementales" a "Memorial de Isla Negra”. 1954-1964. Ed. Hernán Loyola. Barcelona: Galaxia Gutenberg/ Círculo de Lectores, 1999. 1141-1330.

Incitación al nixonicidio y alabanza de la revolución chilena. Obras completas. Tomo III. De "Arte de pájaros" a "El mar y las campanas”. 1966-1973. Ed. Hernán Loyola. Barcelona: Galaxia Gutenberg/Círculo de Lectores, 2000. 705-741.

"Carta de Neruda a Héctor Eandi", 24 de abril de 1929. Obras completas. Tomo V. Nerudiana dispersa II. Ed. Hernán Loyola. Barcelona: Galaxia Gutenberg/Círculo de Lectores, 2001. 941-944. 
"Conducta y poesía". Caballo Verde para la Poesía $\mathrm{N}^{\circ}$ 3, Madrid, diciembre de 1935. Obras completas. Tomo IV. Nerudiana dispersa I. Ed. Hernán Loyola. Barcelona: Galaxia Gutenberg/Círculo de Lectores, 2001. 383-384.

"Diurno de Singapore". La Nación, Santiago, 5 de febrero de 1928. Obras completas. Tomo IV. Nerudiana dispersa I. Ed. Hernán Loyola. Barcelona: Galaxia Gutenberg/Círculo de Lectores, 2001. 339-342.

"El rector ha tenido palabras magníficas...". Discurso pronunciado en la donación de su biblioteca personal a la Universidad de Chile, 20 de junio de 1954. Obras completas. Tomo IV. Nerudiana dispersa I. Ed. Hernán Loyola. Barcelona: Galaxia Gutenberg/Círculo de Lectores, 2001. 945-949.

"España no ha muerto", Discurso pronunciado en Montevideo, en marzo de 1939, ante el Congreso Internacional de las Democracias. Obras completas. T. IV. Nerudiana dispersa I. Edición de Hernán Loyola. Barcelona: Galaxia Gutenberg/Círculo de Lectores, 2001. 422-429.

"Mariano Latorre, Pedro Prado y mi propia sombra". Discurso leído por Pablo Neruda el 30 de marzo de 1962 en el Salón de Honor de la Universidad de Chile, en el acto de su incorporación como Miembro Académico de la Facultad de Filosofía y Educación. Obras completas. Tomo IV. Nerudiana dispersa I. Ed. Hernán Loyola. Barcelona: Ed. Galaxia Gutenberg/Círculo de Lectores, 2001. 1082-1101.

"Mi país, como ustedes saben...". Discurso leído durante el Congreso Latinoamericano de Partidarios de la Paz, Ciudad de México, septiembre de 1949. Obras completas. Tomo IV. Nerudiana dispersa I. Ed. Hernán Loyola. Barcelona: Galaxia Gutenberg/Círculo de Lectores, 2001. 761-769.

"Al recibir el premio Atenea en Concepción". Fechado en Isla Negra, 12 de agosto de 1966. Obras Completas. Tomo V. Nerudiana dispersa II. Ed. Hernán Loyola. Barcelona: Galaxia Gutenberg/Círculo de Lectores, 2002. 117-119.

"Conversación frente al océano". Entrevista de Rita Guibert. Isla Negra, 15 al 31 de enero de 1970. Obras completas. Tomo V. Nerudiana dispersa II. Ed. Hernán Loyola. Barcelona: Galaxia Gutenberg/Círculo de Lectores, 2002. 1110-1182.

"Sonata con recuerdos". Reflexiones desde Isla Negra, 22 de mayo de 1968. Obras completas. Tomo V. Nerudiana dispersa II. Ed. Hernán Loyola. Barcelona: Galaxia Gutenberg/Círculo de Lectores, 2002. 162-165.

Piglia, Ricardo. "Sin mundos imaginarios la vida sería más desdichada". Entrevista de Darío Oses. Cuadernos 58 (2006): 35.

Ricoeur, Paul. Tiempo y narración. Tomo III. México: Ed. Siglo XXI, 1996.

Schidlowsky, David. Las furias y las penas. Pablo Neruda y su tiempo. Berlín: Wissenschaftlicher Verlag, 2003. 